\title{
Inter- and Intra-hospital Transport of the Critically Ill
}

\author{
Thomas C Blakeman MSc RRT and Richard D Branson MSc RRT FAARC
}

\author{
Introduction \\ Inter-hospital Transport \\ Pediatric and Infant Transport \\ Transport Teams \\ Patient Monitoring \\ Adverse Events \\ Minimizing Risk \\ Specialized Therapy \\ ECMO \\ Adult Transport \\ Risks and Benefits of Transport \\ Patient Monitoring \\ Adverse Events \\ Transport of Trauma Patients \\ The Transport Team \\ Inter-hospital Mechanical Ventilation During Transport \\ Intra-hospital Transport \\ Adverse Events \\ Adverse Event Prevention/Mitigation \\ Capnography \\ Ventilators for Transport \\ New Generation Transport Ventilators \\ MRI Transport \\ Summary
}

Intra- and inter-hospital transport is common due to the need for advanced diagnostics and procedures, and to provide access to specialized care. Risks are inherent during transport, so the anticipated benefits of transport must be weighed against the possible negative outcome during the transport. Adverse events are common in both in and out of hospital transports, the most common being equipment malfunctions. During inter-hospital transport, increased transfer time is associated with worse patient outcomes. The use of specialized teams with the transport of children has been shown to decrease adverse events. Intra-hospital transports often involve critically ill patients, which increases the likelihood of adverse events. Radiographic diagnostics are the most common in-hospital transport destination and the results often change the course of care. It is recommended that portable ventilators be used for transport, because studies show that use of a manual resuscitator alters blood gas values due to inconsistent ventilation. The performance of new generation transport ventilators has improved greatly and now allows for seamless transition from ICU ventilators. Diligent planning for and monitoring during transport may decrease adverse events and reduce risk. Key words: patient transport; adverse events; monitoring; portable ventilators; transport teams. [Respir Care 2013;58(6):1008-1021. (C) 2013 Daedalus Enterprises] 
INTER- AND INTRA-HOSPITAL TRANSPORT OF THE CRITICALly ILL

\section{Introduction}

Intra-hospital and inter-hospital transport of mechanically ventilated patients is a common occurrence when providing modern medical care. Advanced diagnostic procedures often require patients to be transported within areas of the hospital or across town to facilities that house the specialized equipment to perform the testing. Although there are risks associated with patient transport, the benefits of this specialized care may outweigh the risk. ${ }^{1,2}$ Additionally, patients must be transported to and from the operating suite and from the emergency department to the ICU. Until several years ago, manual ventilation was the preferred method for patient transport, owing to the poor performance of transport ventilators. ${ }^{3,4}$ Manual ventilation presents another set of problems, including the inability to control airway pressure and/or tidal volume $\left(\mathrm{V}_{\mathrm{T}}\right)$, resulting in hyper- or hypo-ventilation and the possibility of inducing or exacerbating lung injury. ${ }^{5-7}$ Additionally, the maintenance of a stable PEEP is problematic, and spontaneous breathing is difficult. The purpose of this paper is to evaluate current practices in patient transport, including the ventilators used, safety, monitoring capabilities, and evidence-based recommendations and guidelines.

\section{Inter-hospital Transport}

Systems for transporting patients were born primarily from military needs. The transportation of injured soldiers has been documented as far back as the early 1800s, during the Napoleonic wars. Dominique Jean Larrey is credited for creating the initial concepts of military transport medicine. ${ }^{8}$ He recognized the importance of triage of the injured and of providing caregivers with specialized training to use in the field. He also recognized the need to

The authors are affiliated with the Division of Trauma and Critical Care, Department of Surgery, University of Cincinnati College of Medicine, Cincinnati, Ohio.

Mr Blakeman presented a version of this paper at the 51st RESPIRATORY CARE Journal Conference, "Adult Mechanical Ventilation in Acute Care: Issues and Controversies," held September 7 and 8, 2012, in St Petersburg, Florida.

The authors have disclosed relationships with General Electric, Impact Instrumentation, CareFusion, Hamilton Medical, and Newport Medical Instruments. Mr Branson has also disclosed relationships with Advanced Circulatory Systems, Ikaria, Covidien, and Breathe Technologies.

Correspondence: Thomas C Blakeman MSc RRT, Division of Trauma and Critical Care, Department of Surgery, University of Cincinnati, 231 Albert Sabin Way, Cincinnati OH 45267-0558. E-mail: Thomas.Blakeman @ uc.edu.

DOI: $10.4187 /$ respcare.02404 rapidly transport the wounded to a medical facility, and employed a large, horse-drawn carriage with specialized caregivers on board to carry out this task. Civilian transport systems have been refined based on battlefield evacuation techniques and treatments over the last 150 years. The most recent method of transport introduced to civilian medicine from the military experience is the rotary wing air ambulance. This method of evacuation of the wounded war fighter was used extensively in the 1950s and 1960s during the Korean and Vietnam wars. ${ }^{8}$

\section{Pediatric and Infant Transport}

The majority of the available literature on the transport of children addresses transport between facilities to acquire specialized care. Civilian neonatologists and trauma surgeons began using military transport techniques for their patients in the 1960s. Pediatric transport evolved from the initial experience with neonatal transport in the 1970s. ${ }^{8}$ Several studies describe as much as a $50 \%$ improvement in mortality rates in children who were transported to and received care at tertiary centers. ${ }^{9-13}$ Not surprisingly, transfers from ICU to ICU had higher mortality and greater resource utilization than emergency department to ICU transfers. ${ }^{14,15}$ The need for such specialized care has led to the proliferation of neonatal and pediatric ICUs over the past 2 decades. Safely and efficiently transporting patients in need of specialized care is the goal for transport teams.

\section{Transport Teams}

Pediatric and neonatal transport teams are an extension of the ICU. There is no national standard for team composition; it can vary by region and hospital, but often includes nurses, respiratory therapists, physicians, emergency medical technicians, and paramedics. A survey of 229 neonatal transport teams reported that the combination of a registered nurse and a registered respiratory therapist was the most common for specialized teams. ${ }^{16}$ Although data indicate that a physician is not required in half of the transports, ${ }^{17}$ specially trained team members are the key to safe pediatric transport. Orr et al provide strong evidence that using specialized transport teams results in lower adverse events (AEs) and increased survival: $23 \%$ versus $9 \%$ (specialized vs non-specialized teams) during inter-hospital transport. ${ }^{18}$ Unplanned events were more common with non-specialized teams (61\% vs $1.5 \%)$. The point of specially trained teams is to take the ICU to the patient in a controlled fashion, not rushing the patient to the ICU. Orr's group showed that transport teams adhering to this model spent nearly twice as long at the scene and took twice as long to get to the hospital, but had better outcomes. 
Table 1. Transport Equipment and Supplies

\begin{tabular}{|c|c|}
\hline Type & Examples \\
\hline Monitoring equipment & $\begin{array}{l}\text { Electrocardiograph leads and cables, } \\
\text { pulse oximetry probes and cables, } \\
\text { thermometer, stethoscope, blood } \\
\text { pressure cuff }\end{array}$ \\
\hline Suction equipment & $\begin{array}{l}\text { Suction catheters, Yankauer, suction } \\
\text { tubing }\end{array}$ \\
\hline $\begin{array}{l}\text { Intravenous/intra-osseous } \\
\text { equipment }\end{array}$ & $\begin{array}{l}\text { Angiocatheters, arm boards, intra- } \\
\text { osseous needles, tourniquets, tape, } \\
\text { tegaderm, gauze }\end{array}$ \\
\hline $\begin{array}{l}\text { Chest tube/needle drainage } \\
\text { equipment }\end{array}$ & $\begin{array}{l}\text { Chest tubes, pleurovacs, syringes, } \\
\text { stopcocks }\end{array}$ \\
\hline Nasogastric/urinary equipment & $\begin{array}{l}\text { Feeding tubes, nasogastric tubes, } \\
\text { Foley catheters, syringes }\end{array}$ \\
\hline Sterile field supplies & $\begin{array}{l}\text { Betadine, chlorhexidine, alcohol } \\
\text { wipes, sterile gloves, sterile } \\
\text { drapes }\end{array}$ \\
\hline Communication equipment & Cell phones, 2-way radios \\
\hline Intubation equipment & $\begin{array}{l}\text { Endotracheal tubes, nasal and oral } \\
\text { airways, } \mathrm{CO}_{2} \text { detectors, stylets, } \\
\text { laryngeal mask airways, tape, } \\
\text { Magill forceps, commercial tube } \\
\text { holders, tracheostomy tubes }\end{array}$ \\
\hline Laryngoscopy equipment & $\begin{array}{l}\text { Laryngoscope blades and handles, } \\
\text { batteries, bulbs }\end{array}$ \\
\hline Oxygen-related equipment & $\begin{array}{l}\text { Nasal cannulas, oxygen tubing, flow } \\
\text { meters, head hood, self-inflating } \\
\text { bags, resuscitation masks, simple } \\
\text { masks, venturi masks, non- } \\
\text { rebreather masks }\end{array}$ \\
\hline Aerosol equipment & $\begin{array}{l}\text { Aerosol mask, tracheostomy mask, } \\
\text { aerosol tubing, sterile water, } \\
\text { nebulizers }\end{array}$ \\
\hline Miscellaneous & $\begin{array}{l}\text { Defibrillator pads, tape, needles, } \\
\text { cervical collars, butterfly } \\
\text { catheters, syringes, blankets }\end{array}$ \\
\hline
\end{tabular}

\section{Patient Monitoring}

Patient monitoring during transport is an important safety issue. Since the evidence shows that bringing the ICU to the patient is important to completing a successful transport, having the monitoring capabilities of the ICU as well as an array of equipment and supplies available on transport would enhance transport safety. Horowitz and Rosenfeld ${ }^{19}$ provide the recommended equipment and supplies needed for the transport of children (Tables 1 and 2). It is intuitive that the more information the transport team can obtain about the patient's status before transport, the less likely are unexpected events. In a randomized controlled trial conducted by Stroud et al, continuous noninvasive monitoring of blood pressure was compared to intermittent blood pressure monitoring by cuff during transport of 94
Table 2. Transport Medications

\begin{tabular}{|c|c|}
\hline Type & Examples \\
\hline Narcotic analgesics & Fentanyl, morphine, hydromorphone \\
\hline Resuscitation medications & $\begin{array}{l}\text { Atropine, epinephrine, calcium, sodium } \\
\text { bicarbonate }\end{array}$ \\
\hline Sedatives & Ketamine, midazolam \\
\hline Anti-arrythmics & Amiodarone, adenosine, lidocaine \\
\hline Anti-hypertensives & Labetalol, metoprolol, atenolol \\
\hline Neuromuscular blockers & $\begin{array}{l}\text { Succinylcholine, rocuronium, } \\
\text { vecuronium }\end{array}$ \\
\hline Reversal agents & Naloxone \\
\hline Bronchodilators & $\begin{array}{l}\text { Albuterol, ipratropium, } \\
\text { methylprednisolone }\end{array}$ \\
\hline Anti-microbials & $\begin{array}{l}\text { Ampicillin, vancomycin, gentamicin, } \\
\text { ceftriaxone }\end{array}$ \\
\hline Anti-epileptics & $\begin{array}{l}\text { Fosphenytoin, lorazepam, } \\
\text { phenobarbital, diazepam }\end{array}$ \\
\hline Intravenous fluids & $\begin{array}{l}\text { Normal saline, lactated ringers, } 10 \% \\
\text { dextrose, } 5 \% \text { dextrose, albumin }\end{array}$ \\
\hline Intravenous medications & $\begin{array}{l}\text { Dopamine, dobutamine, epinephrine, } \\
\text { lidocaine, insulin }\end{array}$ \\
\hline Anaphylaxis agents & $\begin{array}{l}\text { Racemic epinephrine, cimetidine, } \\
\text { diphenhydramine }\end{array}$ \\
\hline Miscellaneous & $\begin{array}{l}\text { Acetaminophen, activated charcoal, } \\
\text { furosemide, heparin, mannitol, } 3 \% \\
\text { saline, calcium gluconate, dextrose }\end{array}$ \\
\hline (Data from reference 19.) & \\
\hline
\end{tabular}

pediatric patients. ${ }^{20}$ The hypothesis of the study was that continuous blood pressure monitoring would facilitate more timely interventions and improve outcome. In the continuous measurement group, systolic, diastolic, and mean arterial pressure were lower. This group also received more resuscitation interventions, received more intravenous fluids, and had a significantly shorter hospital stay. However, ICU stay was not different between groups. Although the sample size was relatively small, this study shows that more frequent monitoring may lead to timely interventions and improve outcome during the transport of children.

\section{Adverse Events}

Avoiding AEs during inter-hospital transport is the primary goal in providing a safe transport. While many transports are uneventful, sometimes the patient's condition deteriorates as a consequence of disease progression. $\mathrm{Pa}-$ tient monitoring is difficult during transport, due to noise, limited space for the caregivers, and low light. In a study from the United Kingdom, 56 children were prospectively monitored for AEs during inter-hospital transport. Seventy-five percent of the patients experienced important complications, with $20 \%$ of those being life-threatening. The most common AEs were hypothermia, drug errors, tachy- 
INTER- AND INTRA-HOSPITAL TRANSPORT OF THE CRITICALly ILL

cardia, procedure errors, loss of intravenous access, and cyanosis. Life-threatening events included cardiac arrest, bradycardia, hypotension, and inadequate respiratory support as a result of failed oxygen systems and ventilator malfunctions. Although not categorized in this study, the most frequent equipment failure was battery failure. ${ }^{21}$ In a much larger study by Orr et al, 1,085 children were prospectively monitored during inter-hospital transport, and unplanned events and 28 day mortality were recorded. ${ }^{18}$ Fifty-five of the patients (5\%) experienced unplanned events, which included airway events, cardiopulmonary arrest, equipment failure, hypertension, hypotension, loss of intravenous access, and medication error. Ten percent of the patients died during the 28 day assessment period. It should be noted that in both studies, specialized and non-specialized transport teams were utilized, with the majority of the patients experiencing adverse/unplanned events while being transported by the non-specialized teams. One possible reason for the greater number of AEs with the non-specialized groups is that they tend to focus on getting the patient to definitive care quickly, rather than focusing on stabilization before and during transport.

\section{Minimizing Risk}

Currently, there is no mandatory regulatory oversight for transport teams. The Commission on Accreditation of Medical Transport Systems is the only accrediting body, but participation is voluntary and only $20 \%$ of transport teams have received accreditation. There are few Joint Commission transport related requirements. It is the responsibility of individual facilities to monitor and train transport teams. The literature offers several suggestions for decreasing the rate of complications during transport. Bringing the ICU to the patient is the first step in this process. Getting the patient to the receiving facility quickly is important, but not at the risk of the patient becoming unstable. Enhancing monitoring capabilities may provide caregivers with vital information to avert AEs by providing earlier interventions. Finally, utilizing specialized transport teams that focus on patient stabilization appears to be the most effective way to avoid potential life threatening events during the transport of children. ${ }^{22}$

\section{Specialized Therapy}

Nitric oxide (NO) is often used in the ICU for term and near term infants with severe cardiopulmonary dysfunction. Inter-hospital transport of patients requiring this therapy is performed infrequently, but may be the only way the patient can remain stable when transport is unavoidable. Lutman and Petros describe the use of NO during transport and found that it can be used safely during ground, and fixed wing and rotary wing transport, although the delivery and monitoring system can be cumbersome. ${ }^{23}$ They also recommend mandatory NO delivery training for caregivers, and found that few patients respond to doses $>20 \mathrm{ppm}$. For safety purposes, $\mathrm{NO}$ and $\mathrm{NO}_{2}$ levels must be monitored for the patient as well as for the air inside the ambulance or aircraft. Lowe and Trautwein performed a retrospective review of 88 neonates with persistent pulmonary hypertension or severe hypoxic respiratory failure transported to a tertiary hospital for care. ${ }^{24}$ Sixty patients were started on NO before transport, and 28 were started at the receiving facility. Mortality and extracorporeal membrane oxygenation (ECMO) use were no different in either group. For the surviving patients who did not receive ECMO, total hospital stay and stay at the receiving hospital were significantly less in those patients who had NO started at the referring hospital before transport.

\section{ECMO}

Many hospitals provide ECMO support for children with refractory hemodynamic instability, but lack the ability to transport these patients. Cabrera et $\mathrm{al}^{25}$ reviewed the transports of 38 such patients over a 15 year period, to determine effectiveness and safety. None of the patients had major complications or died during transport, although the authors were quick to add that mobile ECMO is extremely risk laden and expensive. The logistics for their system were challenging, as the equipment was large and cumbersome, measuring $183 \mathrm{~cm}$ long $\times 66 \mathrm{~cm}$ wide $\times 102 \mathrm{~cm}$ high. They recommend maximizing all available therapies before considering transport of these patients. Recently, a portable ECMO device has been approved for use in the United States (Cardiohelp, Maquet, Wayne, New Jersey). The device measures $30 \mathrm{~cm} \times 25 \mathrm{~cm} \times 43 \mathrm{~cm}$, and weighs $10 \mathrm{~kg}$, which greatly enhances the portability and minimizes the footprint inside the transport vehicle, while providing pulmonary and/or circulatory support for up to 6 hours.

\section{Adult Transport}

Inter-hospital transfer of adult patients is common, whether the purpose is to receive specialized treatment or diagnostic procedures, or to receive lower levels of care after acute illness has resolved. Nearly 5\% of Medicare patients will be transferred from one hospital's ICU to another. ${ }^{26} \mathrm{Up}$ to one half of patients suffering a myocardial infarction admitted to a hospital that does not have revascularization capabilities will be transferred to another facility. ${ }^{27,28}$ Trauma victims are frequently transferred from non-trauma hospitals to trauma centers to receive specialized care. A retrospective study conducted by Haas et al showed that $30 \%$ of injured patients admitted to their trauma center were transferred from another facility. ${ }^{29}$ 
Table 3. Risks and Benefits of Transfer

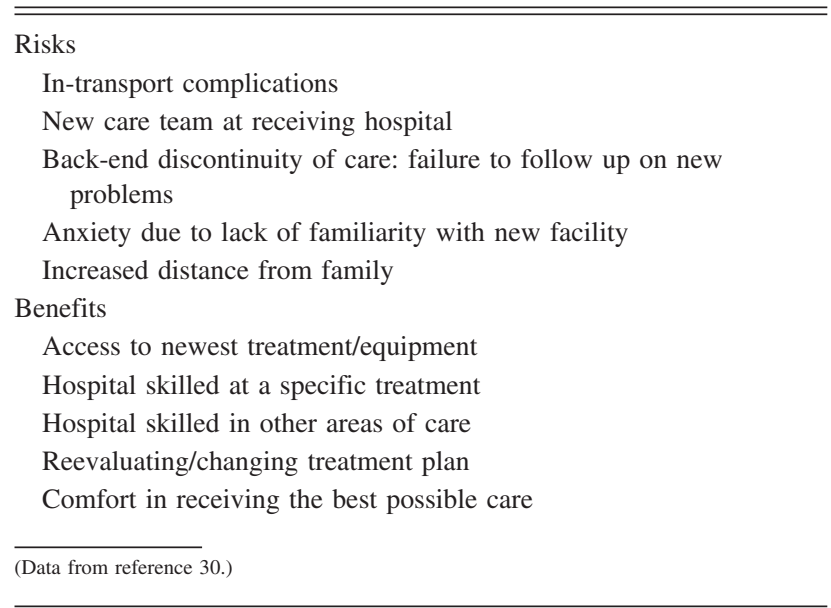

\section{Risks and Benefits of Transport}

The benefits of transport must be weighed against the risks. The anticipated benefit of improved survival provided by transport must greatly exceed the risk of death by precluding transport. The transfer itself imposes its own risk. Table 3 outlines the risk/benefit possibilities of interhospital transfer. ${ }^{30}$ Although there is often patient benefit from transfer to another facility, it comes at a cost. Golestanian et $\mathrm{al}^{31}$ conducted an observational study to identify the outcomes and associated costs when patients were transferred to a tertiary facility. The study showed that transferred patients were sicker, as evidenced by higher Acute Physiology and Chronic Health Evaluation III scores. They had higher ICU and hospital mortality, and longer ICU and hospital stay. On average, transferred patient costs were $\$ 9,600$ higher per ICU admission than non-transferred patients. Interestingly, the patients associated with the highest costs were those with the lowest predicted mortality.

\section{Patient Monitoring}

Similar to the transport of children, critically ill adults should have the same level of physiologic monitoring available in the ICU. At a minimum, continuous electrocardiography, pulse oximetry, blood pressure, heart rate, and breathing frequency monitoring should be used. Depending on the patient, monitoring intracranial pressure, pulmonary artery pressure, continuous arterial pressure, or capnography may be beneficial. For mechanically ventilated patients, the endotracheal tube must be properly secured, its position noted prior to transport and monitored until care is transferred at the receiving hospital. Additionally, $\mathrm{V}_{\mathrm{T}}$ and airway pressures should be continuously monitored and alarms set appropriately to notify caregivers of problems. ${ }^{32}$

\section{Adverse Events}

Transport personnel attempt to avert any problems during patient transport, but inevitably not all transports go smoothly. Adverse events occur, and the role of the caregiver is to recognize problems early and to provide corrective action as soon as possible. Fried et al performed a retrospective review of 2,396 inter-hospital patient ground transfers to determine the reason for transfer and to quantify AEs. ${ }^{33}$ Eighty-nine percent of transports were for special diagnostics or specialist care. Twenty-nine of the 2,396 transports reported AEs. The most common events were monitor failure, infusion pump failure, and unspecified ventilator failure. There was one instance of accidental endotracheal tube dislodgement. No patients died during transport. Of patients requiring mechanical ventilation, equipment failure occurred in $9.8 \%$ of transfers that did not use a dedicated transport team, as opposed to $<1 \%$ of those that did.

In a prospective audit of ground transports of ICU patients in the Netherlands, Ligtenberg and associates ${ }^{34}$ found that AEs occurred in 34 of 100 transports. Interestingly, in $50 \%$ of transports, instructions by the intensivist from the referring hospital were ignored during transport. The authors did not indicate the reason for the deviation from the intensivist instructions.

Respiratory problems were the most common reason for transport, followed by multi-system organ failure and sepsis. Sixty-five percent of the patients were mechanically ventilated. Adverse events ranged from equipment malfunctions to severe physiologic instability. After reviewing records, the authors estimated that $70 \%$ of the AEs could have been avoided by better preparation prior to the transport, through better communication between referring and receiving hospitals, and by the use of a checklist and protocols. ${ }^{34}$

\section{Transport of Trauma Patients}

Barnes et al recorded pulse oximetry and ventilator data from 22 wounded United States soldiers transported via aeromedical evacuation from Iraq to Germany by Air Force Critical Care Air Transport Teams. ${ }^{35}$ The aim of the study was to determine the mechanical ventilatory needs, including oxygen requirements, which is essential to resource planning. $\mathrm{F}_{\mathrm{IO}_{2}}, \mathrm{~V}_{\mathrm{T}}$, minute ventilation, airway pressure, breathing frequency, heart rate, and oxygen saturation were continuously recorded during 117 total flight hours. Set $\mathrm{V}_{\mathrm{T}}$ averaged $8 \mathrm{~mL} / \mathrm{kg}$ or less in 19 of 22 patients. $\mathrm{F}_{\mathrm{IO}_{2}}$ ranged from 0.24 to 1.0 , with an average of 0.49 , which correlated with an average oxygen saturation of $98 \%$. Calculated oxygen usage averaged $3 \mathrm{~L} / \mathrm{min}$ or less in $68 \%$ of the patients (15 of 22). This finding was important in that some commercially available portable oxygen concentra- 
INTER- AND INTRA-HOSPITAL TRANSPORT OF THE CRITICALly ILL

tors have the ability to produce up to $3 \mathrm{~L} / \mathrm{min}$ continuous flow oxygen. This could allow the use of concentrators to provide oxygen to mechanically ventilated patients for transport during mass casualty events, when oxygen resources are scarce.

Although the environment inherent in rotary-wing transport presents the potential for a greater number of AEs, it appears from these reviews that this has not been substantiated in the literature. The occurrence of AEs is comparable with ground transports. The difficulty with direct comparison is lack of consistency or consensus on the definitions used to describe major and minor AEs.

Evidence suggests that there may be a difference in outcome between trauma patients transferred from other facilities and those directly admitted to trauma centers. A meta-analysis of 36 observational studies found that there was no difference in mortality between the 2 groups, although most of the studies did not include patients who died at outlying hospitals. Total costs for transferred patients were higher, and these patients had longer hospital stay than direct admits. ${ }^{36}$

Many patients who are victims of major trauma are taken to trauma centers via rotary-wing transport. The nature of their injuries and the environment within the aircraft, which is noisy and cramped, may increase the chance of AEs. Seymour et al performed a retrospective review of 191 trauma victims transported via rotary-wing aircraft to the hospital of the University of Pennsylvania. ${ }^{37}$ In-flight AEs were the primary outcome of the study. There were no major AEs (death, cardiac arrest, or pneumothorax) recorded during the transports. Twenty-two percent of the patients experienced at least one minor AE, such as oxygen desaturation, in-flight ventilator changes, hypotension, bradycardia, or administration of medications due to physiological disturbances or ventilator asynchrony. In a similar study by Lehman et al, AEs were assessed during 149 rotary-wing transports of ill and injured patients during Operation Iraqi Freedom. ${ }^{38}$ Fifty-three percent of the patients were mechanically ventilated. Along with the challenges of caring for patients in a civilian rotary-wing aircraft, as described above, caregivers for these patients often must work under low light conditions, to avoid any unnecessary attention from insurgents. At least one equipment failure occurred in $17 \%$ of flights, although the types of equipment failures were not characterized. In-flight clinical deterioration, including hypotension, oxygen desaturation, arrhythmia, and tachycardia or bradycardia, occurred on $30 \%$ of the flights. On arrival to the receiving facility, 9\% of the patients required emergency intervention. No deaths or important morbidities were recorded. Many of these patients were critically ill, with $20 \%$ requiring $\geq 10$ units of packed red blood cells at some point prior to transport.

\section{The Transport Team}

Just as with the transport of children, the inter-hospital transport of adults requires a team of highly skilled members. It is recommended that, in addition to the vehicle operator, a minimum of 2 people should accompany the critically ill patient. The team can be a combination of doctors, nurses, respiratory therapists, and paramedics, with each being skilled in advanced airway management and advanced cardiac life support. ${ }^{33}$ McGinn and associates retrospectively examined the transport of 192 multiple trauma and isolated head injury patients by a specialized transport team, as described above. ${ }^{39}$ All but 4 were ground transports, with the longest transport being 120 miles. Eighty-three of the multiple trauma patients required mechanical ventilation. The authors did not report the number of isolated head trauma patients requiring this type of intervention. One patient died during transport, from progressive disease, rather than the actions of the transport team. Based on the outcomes and lack of serious AEs with these trauma patients, the authors recommend the creation of a central retrieval team associated with the local trauma center. The expertise and experience of these team members could have a positive impact on the outcome of transported trauma and other critically ill patients, which may outweigh the cost of training and maintaining such a team.

\section{Inter-hospital Mechanical Ventilation During Transport}

Much has been written about mechanical ventilation practices in the hospital setting, but mechanical ventilation practices during transport and the possible impact on patient outcomes are not well known. It is widely accepted that if lung-protective ventilation strategies are not applied, it can lead to the development of acute lung injury and ARDS. ${ }^{40,41}$ Singh et al performed a retrospective review of 1,735 patients requiring mechanical ventilation who were transported outside the hospital setting. ${ }^{42}$ Ventilation practices and critical events were assessed. The authors found that $60 \%$ of patients were ventilated using volume control, with a mean $\mathrm{V}_{\mathrm{T}}$ of $500 \mathrm{~mL}(6.7 \mathrm{~mL} / \mathrm{kg})$. Predicted body weight was not used, because patient height was not recorded. Instead, they used actual body weight minus $20 \%$ to determine the $\mathrm{V}_{\mathrm{T}}$ delivered. Mean peak inspiratory pressure was $24 \mathrm{~cm} \mathrm{H}_{2} \mathrm{O}$, but plateau pressure was not recorded. Mean PEEP was $5 \mathrm{~cm} \mathrm{H}_{2} \mathrm{O}$, but $22 \%$ were ventilated with PEEP of $<5 \mathrm{~cm} \mathrm{H}_{2} \mathrm{O}$, and zero PEEP was used with 3 patients. Overall, $68 \%$ of patients at risk of acute lung injury/ARDS were ventilated with the authors' calculated and observed protective ventilation thresholds.

Critical events, defined as hypotension, vasopressor use, oxygen desaturation, or in-transport fatality, occurred dur- 
INTER- AND INTRA-HOSPITAL TRANSPORT OF THE CRITICALly ILL

ing $17 \%$ of transports. The most common AE was hypotension, occurring during $11.8 \%$ of all transports, which was frequently associated with administration of sedation. Six of $1,735(0.3 \%)$ patients died during transport. The authors concluded that the ventilator settings were reasonable in relation to peak inspiratory pressures and $\mathrm{V}_{\mathrm{T}}$, although the lack of recorded patient height leaves some doubt as to the accuracy of the predicted body weight calculations.

\section{Intra-hospital Transport}

The majority of the available literature concerning intrahospital transport involves adult patients. Therefore, all information provided in this section pertains to adults unless otherwise noted. Advancements in medical care have given caregivers the ability to prolong patients' lives, which has increased the acuity in the ICU. The safest place for these patients is in the stationary ICU, attached to sophisticated devices and monitors, with close attention by the medical staff. Advancements in medical care have been facilitated by increased diagnostic imaging and procedures, such as computed tomography (CT), magnetic resonance imaging (MRI), nuclear medicine imaging, angiography, and gastrointestinal studies, that require that patients be taken to other areas of the hospital. Hurst et al observed 100 consecutive surgical patients requiring intra-hospital transport, and found that $84 \%$ of those transports were for abdominal CT scan, head CT scan, or angiography..$^{43}$ Transfers from the emergency department to the ICU and/or operating room, or from the ICU to the operating room, also occur with great frequency. It has been suggested that transports within the hospital occur much more often than those outside the hospital, and the in-hospital patients tend to be sicker than those transferred from other facilities. ${ }^{44}$ Undoubtedly, the risk of transport must be weighed against the potential benefit for the patient. Waydhas's review found that diagnostic evaluations of patients changed management in $24-70 \%$ of cases. ${ }^{45}$

\section{Adverse Events}

The first comprehensive review of the literature concerning AEs and their prevention was published by Waydhas in 1999.45 Fanara et al published a review of AEs and recommendations for intra-hospital transport in the published literature for the decade prior to $2009 .{ }^{46}$ Both reviews found that AEs occur in as many as $71 \%$ of inhospital transports. While this appears to be a substantial number, most of the studies reviewed did not differentiate between major and minor AE. Even terminology differed between studies. The terms AEs, unexpected events, and mishaps were often used in the different studies to describe the same events. Given the lack of clear definitions
Table 4. Types of Events Reported as Occurring During Transport

\begin{tabular}{l}
\hline \hline Incorrect identification \\
Systolic blood pressure $>160$ or $<90 \mathrm{~mm} \mathrm{Hg}$ \\
Heart rate $>100$ or $<50$ beats/min \\
Arrhythmia \\
Temperature $<35^{\circ} \mathrm{C}$ \\
Equipment problems \\
$\geq 20$ unit change in heart rate, breathing frequency, blood pressure, \\
intracranial pressure \\
$\geq 5 \%$ reduction in $\mathrm{S}_{\mathrm{pO}_{2}}$ \\
Hypoxia \\
Cardiac arrest \\
Air embolus \\
Increased intracranial pressure \\
Spinal destabilization \\
Hypertension \\
Hypotension \\
Electrocardiographic changes \\
Altered mental status \\
Need for restraints \\
Accidental extubation \\
Monitor battery failure \\
Code activation \\
$\mathrm{S}_{\mathrm{pO}}<90 \%$ \\
Loss of airway \\
Obstructed airway \\
Respiratory arrest \\
Ventilator-associated pneumonia \\
Pneumothorax \\
Hemodynamic instability \\
Bleeding \\
Ventilator failure \\
Oxygen failure \\
Death \\
(Data from references 45 and 46.$)$ \\
\hline
\end{tabular}

of AEs (major, minor, life threatening, et cetera), it is impossible to standardize the results of all the studies. Table 4 shows examples of AEs as they are described in the studies, as events occurring during transport, although the list is not all-inclusive.

Waydhas ${ }^{45}$ was able to broadly categorize AEs in his review. Cardiorespiratory AEs and respiratory complications occurred in up to $47 \%$ and $29 \%$ of transports, respectively. Equipment complications occurred in 10-34\% of transports of mechanically ventilated patients. It was unclear from the reviews what percentage of these complications were from actual ventilator failure. Fanara ${ }^{46}$ found only 2 studies that differentiated AE as minor (physiologic change of $>20 \%$ ) and serious (puts patient's life at risk), and it was reported that a therapeutic intervention was necessary in $80 \%$ of all AEs, whether major or minor. Fanara's review found that, in one study, 22\% of AEs involved the transport ventilator, with two thirds of those 
INTER- AND INTRA-HOSPITAL TRANSPORT OF THE CRITICALly ILL

being untimely alarms and gas or electrical failure. The other major sources of equipment-related AEs were infusion pump and intravenous malfunctions. This review identified the number of infusion pumps, use of catecholamines, level of PEEP, and the emergency nature of the transport as risk factors for AEs. Interestingly, a study published by Papson et al found that most AEs were not related to patient instability and did not adversely affect outcomes. ${ }^{47}$

Bercault et al performed a retrospective matched cohort study to evaluate the effect of intra-hospital transport on the incidence of ventilator-associated pneumonia (VAP). ${ }^{48}$ The authors reviewed 236 patients, half of whom were transported. Duration of mechanical ventilation, antibiotic therapy duration, indication for ventilator support, age, probability of death, mortality rate, and surgical procedures were not different between the 2 groups. The VAP rate was $26 \%$ and $10 \%$ for transported and non-transported patients, respectively. Need for reintubation was also found to be a risk factor for developing VAP. The rates of VAP are in concordance with the results of an earlier study published by Kollef and associates in $1997 .{ }^{49}$ The increased VAP rates for transported patients may be the result of the need to place the patient supine for diagnostic procedures (eg, CT scan or MRI) and/or the manipulation of the endotracheal tube and ventilator circuit, which may facilitate aspiration of secretions from above the endotracheal tube cuff.

\section{Adverse Event Prevention/Mitigation}

There is no shortage of advice on how to prevent or lessen the impact of transport on patients. There are published guidelines provided by the Society of Critical Care Medicine, ${ }^{32}$ American Association for Respiratory Care (AARC), ${ }^{50}$ Study Group for Safety in Anesthesia and Intensive Care, ${ }^{51}$ Intensive Care Society, ${ }^{52}$ and Australasian College for Emergency Medicine, ${ }^{53}$ although most of the guidelines are based on small observational or retrospective studies, or expert opinion. It has been suggested that patients should be accompanied by at least 2 caregivers, one of them a critical care nurse and the other either a doctor or a respiratory therapist, with mechanically ventilated patients. Minimum equipment should include a cardiac monitor with defibrillating capability, airway management equipment, manual resuscitator and mask, oxygen supplies, resuscitation drugs, intravenous fluids, battery operated infusion pumps, and a portable ventilator, as required. ${ }^{45}$ Preventive factors have also been suggested. ${ }^{46}$ Regular patient and equipment checks during transport, careful preparation of the patient, appropriate sedation, use of protocols and check lists, and diagnostic destinations that are easily accessed from the ICU could help limit the number and severity of AEs.
Specialized training has also been recommended for transport of critically ill adult patients. ${ }^{45-47}$ Kue et al evaluated AEs during 3,383 intra-hospital transports of patients using a dedicated transport team at Johns Hopkins, which was adopted from their inter-hospital transport team model. ${ }^{54}$ The reported AE rate was $1.7 \%$. The most common AEs were hypoxia and hypertension and hypotension. The most common interventions were oxygen and vasopressor manipulations. Even though the low AE rate was impressive, due to the cost of training and maintaining a dedicated transport team it is unlikely this model will be universally adopted unless a clear mortality benefit can be shown through randomized controlled trials.

Pre-transport check lists and in-transport monitoring tools have been suggested as ways to decrease AE during transport. ${ }^{55-57}$ Figure 1 shows an example of such a tool. ${ }^{56}$ Choi et al reported a decrease in overall $\mathrm{AE}$ rate, from $36 \%$ to $22 \%$, and a decrease in serious $\mathrm{AE}$ rate, from $9 \%$ to $5 \%$, with the use of a transport checklist with patients transported from the emergency department to the operating room, MRI, CT, or other interventions, ICU, or general wards. ${ }^{55}$

\section{Capnography}

Capnography is widely used in the pre-hospital and emergency department settings and is the standard of care for intubation verification, cardiopulmonary resuscitation effectiveness, neonatal and pediatric transport, military transport, and in the operating room. ${ }^{58-61}$ The evidence for when and in which adult transport patients to use capnography is mixed. Walsh et al reviewed published papers concerning capnography use during mechanical ventilation for 1990 to $2010 .{ }^{62}$ This review was used as the basis for the AARC clinical practice guideline (CPG) on capnography use. Based on the available evidence, the recommendations from this group are to use capnography/end-tidal $\mathrm{CO}_{2}$ $\left(\mathrm{P}_{\mathrm{ETCO}_{2}}\right)$ monitoring for all endotracheal tube confirmations and all transports of patients requiring mechanical ventilation. The CPG also suggests its use for other purposes that are beyond the scope of this paper. Palmon et al conducted a randomized analysis of capnography use to guide ventilation, versus blinded capnography measurements, during 50 patient transports from the operating room to the ICU or the ICU to radiology. ${ }^{63}$ Arterial blood gas analyses were done before and after transport, which showed that there was no significant differences in $\mathrm{P}_{\mathrm{aCO}}$ in either group. The recommendation from these results is that capnography is not needed for short transports, although it may be of some benefit to those patients who require tight control of $\mathrm{P}_{\mathrm{aCO}}$ (ie, patients with traumatic brain injury). Two other prospective studies of intubated trauma patients showed that monitoring and guiding ventilation via capnography resulted in a significantly higher 
INTER- AND INTRA-HOSPITAL TRANSPORT OF THE CRITICALly ILL

Transport Record ICU

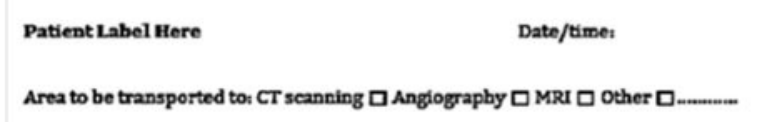

Pre-transport checklist:
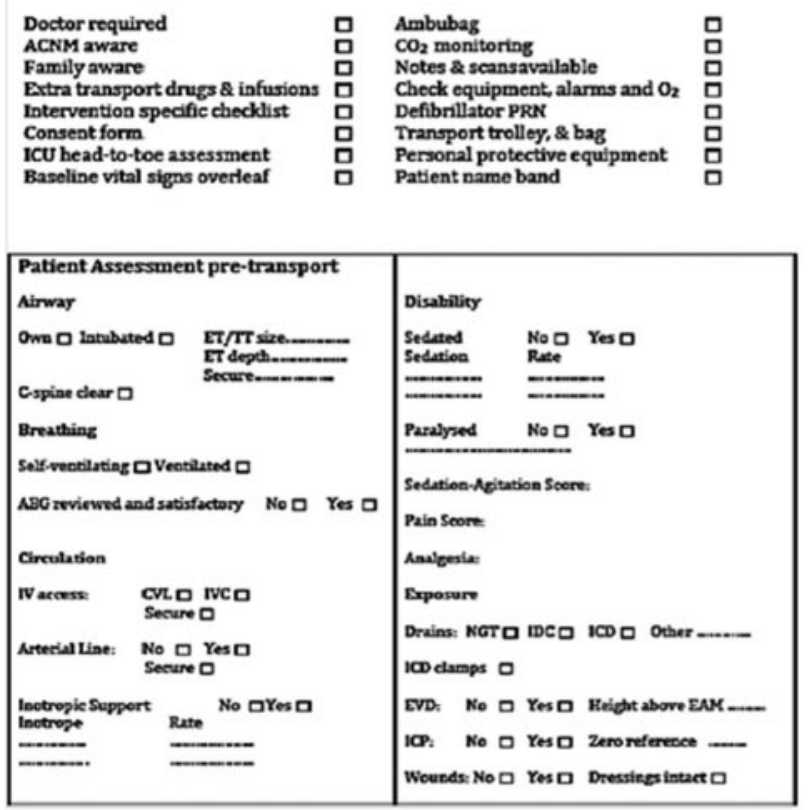

Side one
Patient Label Here
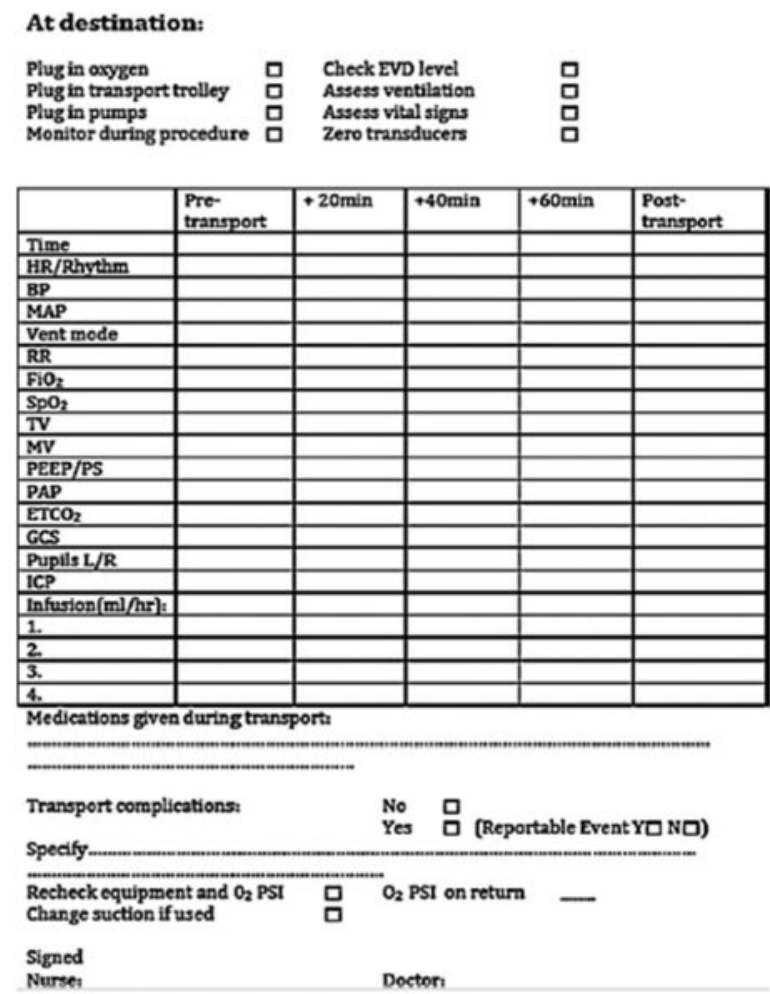

Side two

Fig. 1. Transport checklist and monitoring tool. (From reference 56, with permission.)

incidence of normo-ventilation and a lower incidence of hypo-ventilation during transport. ${ }^{61,64}$ Again, the recommendation is for use of capnography with those patients who require close control of $\mathrm{P}_{\mathrm{aCO}}$ (ie, those patients with head injuries).

\section{Ventilators for Transport}

Transport ventilators are utilized in prehospital, interand intra-hospital transport, military transport, and civilian disaster response. Although important improvements have been made in the performance of transport ventilators, manual resuscitators are still frequently used in the transport of patients to and from the operating room and from the emergency department to the ICU, diagnostics, or the operating room. Although the use of a manual resuscitator is easy and does not require a specialized skill set, alterations in the patient's respiratory status and arterial blood gas values can occur. Gervais et $\mathrm{al}^{65}$ and Hurst et al ${ }^{66}$ observed severe respiratory alkalosis during intra-hospital transport in prospective randomized trials, comparing ventilation with a manual resuscitator to a transport ventilator. Braman and associates also observed the same ventilation and blood gas changes, in addition to hemodynamic changes of hypotension, and arrhythmias that were significantly correlated to blood gas alterations. ${ }^{67}$ In a bench model, Hess and Simmons found substantial increases in resistance with some manual resuscitators, which could increase work of breathing in spontaneously breathing patients. ${ }^{68}$ Nakamura et al compared ICU physicians ventilating patients during transport with a manual resuscitator to transport with a portable ventilator, and found that the use of a portable ventilator provided more consistent ventilation and that patients were less likely to have a deterioration in oxygenation. ${ }^{5}$

Due to the variability in respiratory parameters and the possible deterioration of blood gases and changes in hemodynamics during manual resuscitator use, portable ventilators have become the preferred method for transporting patients within and outside the hospital. In the prehospital setting the use of a transport ventilator should provide a stable minute ventilation and, more importantly, free up a caregiver to perform other tasks. In the hospital setting a transport ventilator should provide the same settings as on the patient's ICU ventilator. Although there are often more people available to assist with the transport, ICU patients tend to be the most critically ill and are often on more aggressive ventilator settings as a result of their disease 
process. The AARC CPG provides minimum recommendations for transport ventilators. ${ }^{50}$ At a minimum, whether used in or out of the hospital setting, the transport ventilator should provide: battery power sufficient to finish the transport; full ventilatory support; independent control of $\mathrm{V}_{\mathrm{T}}$ and breathing frequency; stable $\mathrm{V}_{\mathrm{T}}$ with changing lung compliance; a disconnect alarm; airway pressure monitoring; stable PEEP; and $\mathrm{F}_{\mathrm{IO}_{2}}$ up to 1.0.5 Other desirable features for transport ventilators are: rugged, lightweight, and easy to use; low gas consumption; easy to trigger; both volume and pressure modes; adjustable $\mathrm{F}_{\mathrm{IO}_{2}}$; and ability to operate from a $50 \mathrm{psi}_{2}$ source. ${ }^{69}$

Since the late 1990s there have been several papers detailing evaluations of some or all of the performance characteristics of transport ventilators, including triggering, work of breathing, battery life, intrinsic PEEP, and $\mathrm{V}_{\mathrm{T}}$ delivery. ${ }^{70-74}$ As technology has improved, the performance of many but not all of the devices showed advances with each subsequent model of ventilator introduced. Spurred by the need to transport the sickest of patients for diagnostics and procedures, recent research into the performance of the available transport ventilators has been accomplished.

Chipman and associates evaluated 11 "simple" and 4 "sophisticated" ventilators in a bench and animal model. 75 The sophisticated devices were electrically powered (battery or alternating current), had multiple modes and allowed spontaneous breathing, provided an adjustable range of $\mathrm{F}_{\mathrm{IO}_{2}}$ settings, and provided adjustable PEEP. The simple devices lacked one or more of these characteristics. The goals of the study were to determine which ventilators could ventilate both injured and healthy lungs and provide specifically set $\mathrm{V}_{\mathrm{T}}$ and breathing frequency settings in both the animal and bench model, and to determine which devices were most appropriate to transport patients in various settings.

The results of the study showed that all the devices were able to ventilate the healthy animals' lungs. Only 4 of the devices were able to ventilate the injured lungs. Breathing frequency settings were the limiting factor in those devices that could not. With the bench evaluation, only 6 devices could achieve the breathing frequency and $\mathrm{V}_{\mathrm{T}}$ target settings. In those that could not achieve the targets, it was most often due to variation in $\mathrm{V}_{\mathrm{T}}$, due to increased airway resistance and/or decreased lung compliance. There are important limitations in this study, which include the use of a pediatric sized animal and the use of up to 5 devices on the same animal. Five of the 14 devices were able to operate by battery power alone, but the battery duration differed considerably (75-490 $\mathrm{min}$ ). The time required to deplete the usable $\mathrm{O}_{2}$ from an E-size cylinder ranged from 30 to $77 \mathrm{~min}$ on $\mathrm{F}_{\mathrm{IO}_{2}}$ of 1.0. The investigators determined that, with combined bench and animal testing, only 2 of the 15 transport ventilators met all the targets and would

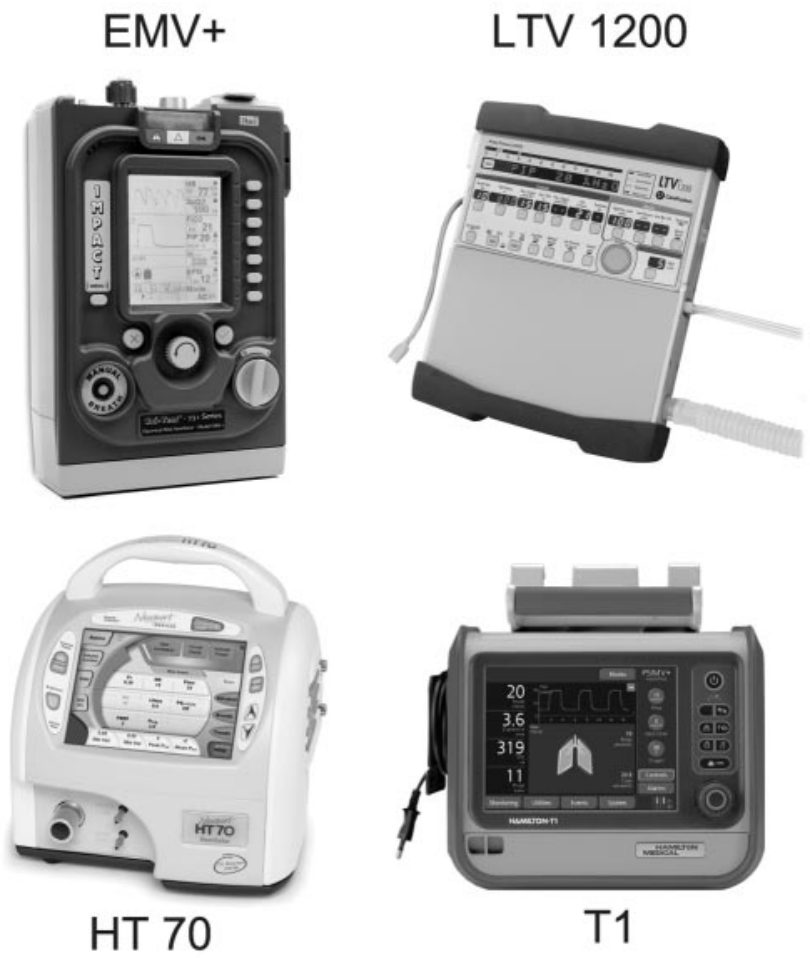

Fig. 2. Portable ventilators used for performance evaluation. EMV+ image courtesy of Impact Instrumentation. LTV 1200 image courtesy of CareFusion. HT70 image courtesy of Newport Medical. T1 image courtesy of Hamilton Medical.

be the most appropriate to use when transporting patients with high ventilatory requirements.

\section{New Generation Transport Ventilators}

Over the past few years, several new transport ventilators have been introduced, with claims of increased performance and features over previous models. Our group evaluated 4 of the newest devices available for sale in the United States in a bench study. ${ }^{76}$ All devices are considered to be sophisticated, based on the work of Austin et al ${ }^{6}$ and Chipman. ${ }^{75}$ We evaluated the EMV (Impact Instrumentation, West Caldwell, New Jersey), LTV 1200 (CareFusion, San Diego, California), HT70 (Newport Medical, Costa Mesa, California), and T1 (Hamilton Medical, Reno, Nevada) (Fig. 2) in terms of triggering response, $V_{T}$ and $\mathrm{F}_{\mathrm{IO}_{2}}$ accuracy, gas consumption, and battery duration. Unlike many previous generation transport ventilators, all but one of the devices utilized flow triggering. Historically, flow triggering was superior to pressure triggering due to the slow response time and effort required to open the demand valves. The triggering delay time (Fig. 3), which is a good indicator of the responsiveness to patient effort and work of breathing, was comparable between all 4 devices, including the EMV, which was pressure trig- 
INTER- AND INTRA-HOSPITAL TRANSPORT OF THE CRITICALly ILL

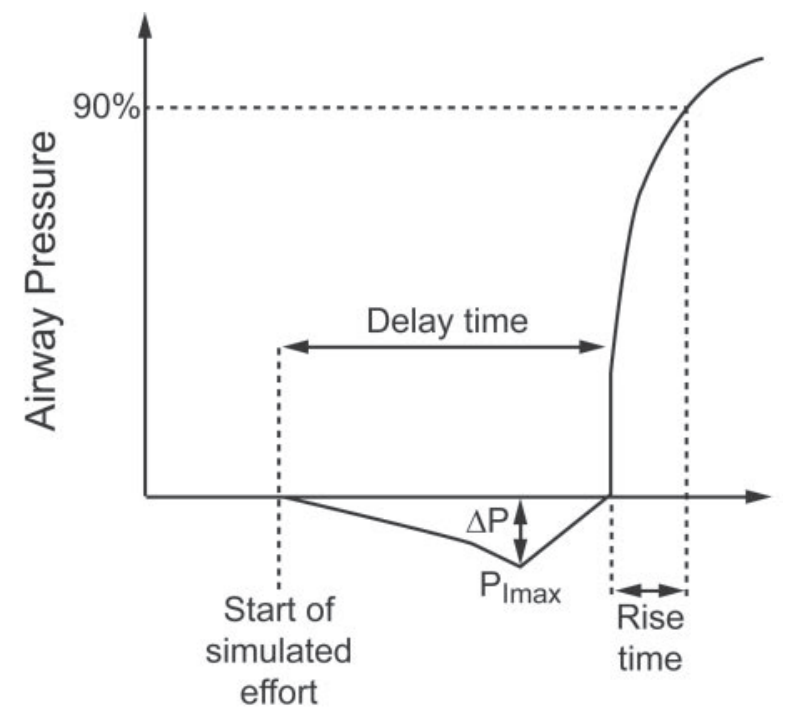

Time

Fig. 3. Triggering evaluation diagram showing delay time, rise time, and maximum negative inspiratory pressure $\left(P_{\text {Imax }}\right)$.

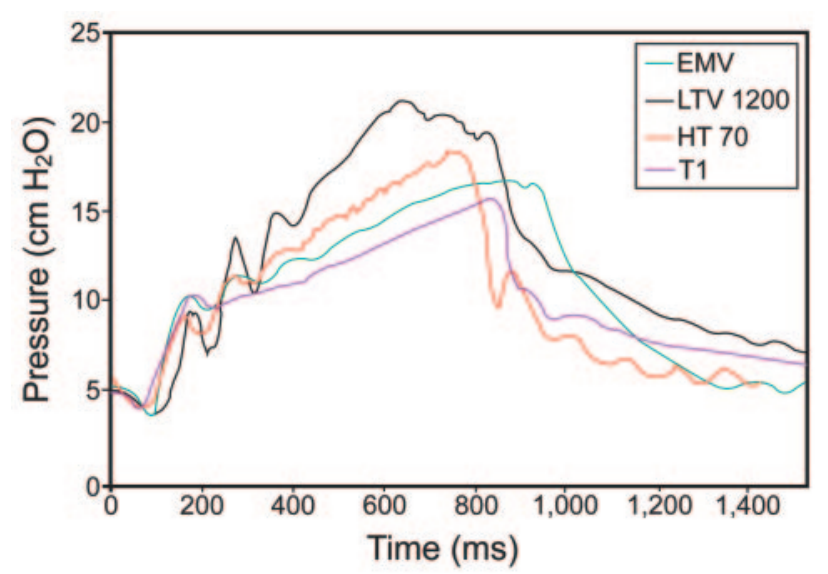

Fig. 4. Representative breaths with each device, using aggressive effort, fast rise time, and pressure support of $10 \mathrm{~cm} \mathrm{H}_{2} \mathrm{O}$.

gered. The rise time differed among devices, due to the algorithm used for the rise time profile with each device. Figure 4 shows representative waveforms with each device, using a simulated aggressive inspiratory effort. Interestingly, the ventilators that had the fastest rise time profile overshot the set pressure to a greater degree. $\mathrm{V}_{\mathrm{T}}$ accuracy was comparable between ventilators. $\mathrm{F}_{\mathrm{IO}_{2}}$ accuracy was comparable among the devices, with the exception of the EMV at $\mathrm{F}_{\mathrm{IO}_{2}}<0.4$ and the LTV 1200 at $\mathrm{F}_{\mathrm{IO}_{2}}$ $>0.6$, which were $> \pm 5 \%$ of set $\mathrm{F}_{\mathrm{IO}_{2}}$. Gas consumption and battery duration were the areas that showed the widest differences between devices. Gas consumption differences were due to use of bias flow. Battery duration differences were due to the battery type, operating characteristics, and drive mechanism (continuous or variable speed turbine or compressor). Although there were some differences between the devices tested, unlike previous transport ventilator evaluations, all met or exceeded the minimum requirements outlined in the AARC CPG.

\section{MRI Transport}

Arguably the most challenging and potentially dangerous transport in terms of logistics, specialized equipment, and patient safety is the transport for magnetic resonance imaging (MRI). There have been reports of office furniture, hospital beds, oxygen tanks, and medical equipment ${ }^{77}$ being pulled into the magnet. Deaths due to objects flying into the magnet, although rare, have also been reported. ${ }^{78}$ Caution must be taken when exposing a patient with implantable devices such as pacemakers and defibrillators, as the magnet many render them inoperable. Also the use of other devices, such as reinforced endotracheal tubes and pulmonary artery and central venous catheters that contain metal wires, has the potential to inflict burns on patients due to the wires heating up when in close proximity to the magnet. MRI suites are often far away from patient care areas, and the procedures performed typically are more lengthy than other diagnostic modalities such as CT scans. Therefore, the intravenous pumps, monitors, ventilators, et cetera must be capable of operating on battery power for extended periods if needed. Equipment being considered for use in the MRI suite will fall under one of 3 categories:

- MRI safe: poses no hazards in an MRI environment

- MRI conditional: suitable under certain specified conditions

- MR unsafe: not suitable for use in an MRI environment

MRI safe equipment is the most desirable because it contains no ferrous material and can be used without regard for distance from the magnet or the equipment function being affected. MRI conditional equipment is functional inside the MRI suite but is composed of some ferrous material or has special shielding and must remain a certain distance from the magnet, depending on the device and the magnet strength. MRI conditional equipment tends to be more sophisticated in terms of monitoring, alarms, and operational capability, but some devices must be tethered in place to ensure that they do not drift toward the magnet. ${ }^{78}$ In some cases, placing the ventilator outside the MRI suite and using an extremely long circuit may be the only option if the facility does not have the appropriate MRI safe or conditional device. Not being directly near the patient means using a longer ventilator circuit, which may affect $\mathrm{V}_{\mathrm{T}}$ due to additional compressible volume lost in the circuit. Patient triggering may also be affected.

MRI is being increasingly used for the diagnosis of disease and injury. Historically, MRI was often delayed 
due to the patient being considered too sick to transport to the suite and monitor during the test, owing to the poor monitoring capabilities and ventilator performance. During the past decade, monitoring inside the MRI suite has improved and now can include pulse oximetry, electrocardiography, and invasive and noninvasive blood pressure monitoring. Typical MRI safe transport ventilators are powered by pressurized oxygen and have very few, if any, audible and/or visual alarms, making safety a major concern. Gas consumption of these ventilators is very high and can empty a full E-size cylinder in 30 min or less, often necessitating transport with 2 or more cylinders. Advantages of these devices include that most are light and can easily be placed in the patient's bed for transport and placed on the MRI table with the patient during the scan. Triggering and flow capabilities are not conducive to spontaneous breathing with some of these ventilators. Chipman et al evaluated 2 MRI safe ventilators and found that both used $100 \%$ oxygen as the power source, and had limited monitoring capability. One had high pressure and disconnect alarms, and the other had no alarms. ${ }^{75}$ It was also found that breathing frequency and/or $\mathrm{V}_{\mathrm{T}}$ changed in response to changes in airway resistance and lung compliance.

MRI conditional ventilators are suitable to use in the MRI suite, but with some restrictions. Since these ventilators often contain some components that are ferrous based, the main restriction is to have the device positioned a certain distance away from the magnet, and usually tethered to prevent drifting toward the magnet. The advantage of these ventilators is enhanced monitoring and alarm capabilities and better patient/ventilator interaction, due to their being ICU comparable. The disadvantage is the requirement for an extra-long ventilator circuit, due to the required distance away from the magnet. Ventilator triggering may be compromised and work of breathing may be increased with use of the longer circuit.

Given the limitations of transport ventilators suitable for MRI use and the monitoring capabilities during the procedure, the decision must be made as to when the transport can be safely accomplished. Since MRI is typically not a life-saving intervention, ideally only "stable" patients would be transported to MRI, although stability as a criterion is open to considerable interpretation. In our trauma/ surgical ICU we have informal criteria, although not in policy form, that we believe describe a patient who is stable enough to endure the transport with the least amount of risk. The patient should have stable vital signs without the use of vasopressors or inotropes, blood pressure that can tolerate sedation, set ventilator breathing frequency $\leq 20$ breaths/min, PEEP $\leq 10 \mathrm{~cm} \mathrm{H}_{2} \mathrm{O}$, and $\mathrm{F}_{\mathrm{IO}_{2}} \leq 0.6$. Even with fairly conservative criteria, the potential remains for the patient's condition to deteriorate, so diligent use of the monitoring available during MRI is warranted.

\section{Summary}

Whether outside or within the hospital, patient transport remains a necessary facet of today's healthcare environment. Advanced diagnostics and centers specializing in the care of difficult diseases and conditions require that patients be moved, often when they are not stable. The additional requirement for mechanical ventilation when transporting the sickest patients renders an already potentially unsafe scenario even more so. The performance of transport equipment, including ventilators, is improving, which enables caregivers to get closer to the goal of bringing the ICU to the patient throughout the transport. Careful planning, monitoring, and resource allocation, including personnel appropriate for the transport, are extremely important to ensure patients remain as safe as possible.

\section{REFERENCES}

1. Stevenson VW, Haas CF, Wahl WL. Intrahospital transport of the adult mechanically ventilated patient. Respir Care Clin N Am 2002; $8(1): 1-35$.

2. Branson RD. Intrahospital transport of the critically ill, mechanically ventilated patient. Respir Care 1992;37(7):775-795.

3. Attebo L, Bengtsson M, Johnson A. Comparison of portable emergency ventilators using a lung model. Br J Anaesth 1993;70(3):372377.

4. Heinrichs W, Mertzlufft F, Dick W. Accuracy of delivered versus preset minute ventilation of portable emergency ventilators. Crit Care Med 1989;17(7):682-685.

5. Nakamura T, Fujino Y, Uchiyama A, Mashimo T, Nishimura M. Intrahospital transport of critically ill patients using ventilator with patient-triggering function. Chest 2003;123(1):159-164.

6. Austin PN, Campbell RS, Johannigman JA, Branson RD. Transport ventilators. Respir Care Clin N Am 2002;8(1):119-150.

7. The Acute Respiratory Distress Syndrome Network. Ventilation with lower tidal volumes as compared with traditional tidal volumes for acute lung injury and the acute respiratory distress syndrome. N Engl J Med 2000;342(18):1301-1308.

8. Ajizian SJ, Nakagawa TA. Interfacility transport of the critically ill pediatric patient. Chest 2007;132(4):1361-1367.

9. Usher RH. The role of the neonatologist. Pediatr Clin North Am 1970;17(1):199-202.

10. Butterfield LJ. Regionalization for respiratory care. Pediatr Clin North Am 1973;20(2):499-505.

11. Pettett G, Merenstein GB, Battaglia FC, Butterfield LJ, Efird R. An analysis of air transport results in the sick newborn infant. Part I: the transport team. Pediatrics 1975;55(6):774-782.

12. Pollack MM, Katz RW, Ruttimann UE, Getson PR. Improving the outcome and efficiency of intensive care: the impact of an intensivist. Crit Care Med 1988;16(1):11-17.

13. Pollack MM, Alexander SR, Clarke N, Ruttimann UE, Tesselaar HM, Bachulis AC. Improved outcomes from tertiary center pediatric intensive care: a statewide comparison of tertiary and nontertiary care facilities. Crit Care Med 1991;19(2):150-159.

14. Odetola FO, Clark SJ, Gurney JG, Dechert RE, Shanley TP, Freed GL. Effect of interhospital transfer on resource utilization and outcomes at a tertiary pediatric intensive care unit. J Crit Care 2009; 24(3):379-386.

15. Odetola FO, Davis MM, Cohn LM, Clark SJ. Interhospital transfer of critically ill and injured children: an evaluation of transfer pat- 


\section{INTER- AND INTRA-HOSPITAL TRANSPORT OF THE CRITICALLY ILL}

terns, resource utilization, and clinical outcomes. J Hosp Medicine 2009;4(3):164-170.

16. Karlson KA, Trautman M, Price-Douglas W, Smith S. National survey of neonatal transport teams in the united states. Pediatrics 2011; 128(4):685-691.

17. McCloskey KA, King WD, Byron L. Pediatric critical care transport: is a physician always needed on the team? Ann Emerg Med 1989; 18(3):247-249.

18. Orr RA, Felmet KA, Han Y, McCloskey KA, Dragotta MA, Bills $\mathrm{DM}$, et al. Pediatric critical care specialized transport teams, compared with nonspecialized teams, are associated with fewer unplanned events and improved survival rates. Pediatrics 2009;124(1):40-48.

19. Horowitz R, Rosenfeld RA. Pediatric critical care interfacility transport. Clin Pediatr Emerg Med 2007;8(3):190-202.

20. Stroud MH, Prodhan P, Moss M, Fiser R, Schexnayder S, Anand K. Enhanced monitoring improves pediatric transport outcomes: a randomized controlled trial. Pediatrics 2011;127(1):42-48.

21. Barry PW, Ralston C. Adverse events occurring during interhospital transfer of the critically ill. Arch Dis Child 1994;71(1):8-11.

22. McPherson ML, Graf JM. Speed isn't everything in pediatric medical transport. Pediatrics 2009;124(1):381-383.

23. Lutman D, Petros A. Inhaled nitric oxide in neonatal and paediatric transport. Early Hum Dev 2008;84(11):725-729.

24. Lowe CG, Trautwein JG. Inhaled nitric oxide therapy during the transport of neonates with persistent pulmonary hypertension or severe hypoxic respiratory failure. Eur J Pediatr 2007;166(10):10251031.

25. Cabrera AG, Prodhan P, Cleves MA, Fiser RT, Schmitz M, Fontenot E. Interhospital transport of children requiring extracorporeal membrane oxygenation support for cardiac dysfunction. Congenit Heart Dis 2011;6(3):202-208.

26. Iwashyna TJ, Christie JD, Moody J, Kahn JM, Asch DA. The structure of critical care transfer networks. Med Care 2009;47(7):787793.

27. Mehta RH, Stalhandske EJ, McCargar PA, Ruane PA, Eagle KA. Elderly patients at highest risk with acute myocardial infarction are more frequently transferred from community hospitals to tertiary centers: reality or myth? Am Heart J 1999;138(4 Pt 1):688-695.

28. Iwashyna TJ, Kahn JM, Hayward RA, Nallamothu BK. Interhospital transfers among Medicare beneficiaries admitted for acute myocardial infarction at nonrevascularization hospitals. Circ Cardiovasc Qual Outcomes 2010;3(5):468-475.

29. Haas B, Gomez D, Zagorski B, Stukel TA, Rubenfeld GD, Nathens AB. Survival of the fittest: the hidden cost of undertriage of major trauma. J Am Coll Surg 2010;211(6):804-811.

30. Iwashyna TJ. The incomplete infrastructure for interhospital patient transfer. Crit Care Med 2012;40(8):2470-2478.

31. Golestanian E, Scruggs JE, Gangnon RE, Mak RP, Wood KE. Effect of interhospital transfer on resource utilization and outcomes at a tertiary care referral center. Crit Care Med 2007;35(6):1470-1476.

32. Warren J, Fromm RE, Orr RA, Rotello LC, Horst HM. Guidelines for the inter- and intrahospital transport of critically ill patients. Crit Care Med 2004;32(1):256-262.

33. Fried MJ, Bruce J, Colquhoun R, Smith G. Inter-hospital transfers of acutely ill adults in Scotland. Anaesthesia 2010;65(2):136-144.

34. Ligtenberg JM, Arnold LG, Stiensrta Y, van der Werf TS, Meertens JH, Tulleken JE, Zijlstra JG. Quality of interhospital transport of critically ill patients: a prospective audit. Crit Care 2005;9(4):R446-R451.

35. Barnes SL, Branson R, Gallo LA, Beck G, Johannigman J. En-route care in the air: snapshot of mechanical ventilation at 37,000 feet. J Trauma 2008;64(2):S129-S135.

36. Hill AD, Fowler RA, Nathens AB. Impact of interhospital transfer on outcomes for trauma patients: a systematic review. J Trauma 2011; 71(6):1885-1901.
37. Seymour CW, Kahn JM, Schwab CW, Fuchs BD. Adverse events during rotary-wing transport of mechanically ventilated patients: a retrospective cohort study. Crit Care 2008;12(3):R71-R80.

38. Lehman R, Oh J, Killius S, Cornell M, Furay E, Martin M. Interhospital transport by rotary wing aircraft in a combat environment: risks, adverse events, and process improvement. J Trauma 2009;66(4): S31-S36.

39. McGinn GH, MacKenzie RE, Donnelly JA, Smith EA, Runcie CJ. Interhospital transfer of the critically ill trauma patient: the potential role of a specialist transport team in a trauma system. J Accid Emerg Med 1996;13(2):90-92.

40. Gajic O, Dara SI, Mendez JL, Adesanya AO, Festic E, Caples SM, et al. Ventilator- associated lung injury in patients without acute lung injury at the onset of mechanical ventilation. Crit Care Med 2004; 32(9):1817-1824.

41. Gajic O, Frutos-Vivar F, Esteban A, Hubmayr RD, Anzueto A. Ventilator settings as a risk factor for acute respiratory distress syndrome in mechanically ventilated patients. Intensive Care Med 2005; 31(7):922-926

42. Singh JM, Ferguson ND, MacDonald RD, Stewart TE, Schull MJ. Ventilation practices and critical events during transport of ventilated patients outside of hospital: a retrospective cohort study. Prehosp Emerg Care 2009;13(3):316-322.

43. Hurst JM, Davis K, Johnson DJ, Branson RD, Campbell RS, Branson PS. Cost and complications during in-hospital transport of critically ill patients: a prospective cohort study. J Trauma 1992;33(4): 582-585.

44. Shirley PJ, Bion JF. Intra-hospital transport of critically ill patients: minimising risk. Intensive Care Med 2004;30(8):1508-1510.

45. Waydhas C. Intrahospital transport of critically ill patients. Crit Care 1999;3(5):R83-R89.

46. Fanara B, Manzon C, Barbot O, Desmettre T, Capellier G. Recommendations for the intra- hospital transport of critically ill patients. Crit Care 2010;14(3):R87-R96.

47. Papson JNP, Russell KL, Taylor DM. Unexpected events during the intrahospital transport of critically ill patients. Acad Emerg Med 2007;14(6):574-755

48. Bercault N, Wolf M, Runge I, Fleury JC, Boulain T. Intrahospital transport of critically ill ventilated patients: a risk factor for ventilator-associated pneumonia—a matched cohort study. Crit Care Med 2005;33(11):2471-2478.

49. Kollef M, Prentice D, Shapiro SD, Silver P, St. John R, Trovillion E. Patient transport from intensive care increases the risk of developing ventilator-associated pneumonia. Chest 1997;112(3):765-773.

50. American Association for Respiratory Care. Clinical Practice Guideline. In-hospital transport of the mechanically ventilated patient. 2002 revision \& update. Respir Care 2002;47(6):721-723.

51. SIAARTI Study Group for Safety in Anesthesia and Intensive Care. Recommendations on the transport of critically ill patients. Minerva Anestesiol 2006;72(10):37-57

52. Intensive Care Society. Guidelines for the transport of the critically illadult,3rdedition. 2011.http://www.ics.ac.uk/professional/guidance transport_3_3_. Accessed March 21, 2013.

53. Australian and New Zealand College of Anaesthetists; Royal Australasian College of Physicians; Australasian College for Emergency Medicine. Minimum standards for transport of critically ill patients. Adopted March 2003. http://www.acem.org.au/media/policies_and _guidelines/min_standard_crit_ill.pdf. Accessed March 21, 2013.

54. Kue R, Brown P, Ness C, Scheulen J. Adverse clinical events during intrahospital transport by a specialized team: a preliminary report. Am J Crit Care 2011;20(2):153-162.

55. Choi HK, Shin SD, Ro YS, Kim DK, Shin SH, Kwak YH. A before and after intervention trial for reducing unexpected events during the 
intrahospital transport of emergency patients. Am J Emerg Med 2012;30(8):1433-1440.

56. Jarden R, Quirke S. Improving safety and documentation in intrahospital transport: development of an intrahospital transport tool for critically ill patients. Intensive Crit Care Nurs 2010;26(2):101-107.

57. Nakayama DK, Lester SS, Rich DR, Weidner BC, Glenn JB, Shaker IJ. Quality improvement and patient care checklists in intrahospital transfers involving pediatric surgery patients. J Pediatr Surg 2012; 47(1):112-116.

58. Eipe N, Doherty DR. A review of pediatric capnography. J Clin Monit Comput 2010;24(4):261-268.

59. Ortega R, Connor C, Kim S, Djang R, Patel K. Monitoring ventilation with capnography. N Engl J Med 2012;367(19):e27.

60. Rhoads C, Thomas F. Capnography: beyond the numbers. Air Med J 2002;21(2):43-48.

61. Helm M, Schuster R, Hauke J, Lampl L. Tight control of prehospital ventilation by capnography in major trauma victims. Br J Anaesth 2003;90(3):327-332.

62. Walsh BK, Crotwell DN, Restrepo RD. American Association for Respiratory Care Clinical Practice Guildelines. Capnography/capnometry during mechanical ventilation: 2011. Respir Care 2011; 56(4):503-509.

63. Palmon SC, Liu M, Moore LE, Kirsch JR. Capnography facilitates tight control of ventilation during transport. Crit Care Med 1996; 24(4):608-611.

64. Hinkelbein J, Floss F, Denz C, Krieter H. Accuracy and precision of three different methods to determine $\mathrm{P}_{\mathrm{CO}_{2}}\left(\mathrm{P}_{\mathrm{aCO}_{2}}\right.$ vs $\mathrm{PetCO}_{2}$ vs $\mathrm{PtcCO}_{2}$ ) during interhospital ground transport of critically ill and ventilated adults. J Trauma 2008;65(1):10-18.

65. Gervais HW, Eberle B, Konietzke D, Hennes HJ, Dick W. Comparison of blood gases of ventilated patients during transport. Crit Care Med 1987;15(8):761-763.

66. Hurst JM, Davis K, Branson RD, Johannigman JA. Comparison of blood gases during transport using two methods of ventilator support. J Trauma 1989;29(12):1637-1640.

67. Braman SS, Dunn SM, Amico CA, Millman RP. Complications of intrahospital transport in critically ill patients. Ann Intern Med 1987; 107(4):469-473.

68. Hess D, Simmons M. An evaluation of the resistance to flow through the patient valves of twelve adult manual resuscitators. Respir Care 1992;37(5):432-438.

69. American Association for Respiratory Care. Guidelines for acquisition of ventilators to meet demands for pandemic flu and mass casualty incidents. Updated 2008. http://www.aarc.org/resources/ vent_guidelines_08.pdf. Accessed March 21, 2013.

70. Austin PN, Campbell RS, Johannigman JA, Branson RD. Work of breathing of seven portable ventilators. Resuscitation 2001;49(2): 159-167.

71. Miyoshi E, Fujino Y, Mashimo T, Nishimura M. Performance of transport ventilator with patient-triggered ventilation. Chest 2000; 118(4):1109-1115.

72. Campbell RS, Johannigman JA, Branson RD, Austin PN, Matacia G, Banks G. Battery duration of portable ventilators: effects of control variable, positive end-expiratory pressure, and inspired oxygen concentration. Respir Care 2002;47(10):1173-1183.

73. Zanetta G, Robert D, Guérin C. Evaluation of ventilators used during transport of ICU patients-a bench study. Intensive Care Med 2002; 28(4):443-451.

74. Rodriquez D, Branson R, Barnes SA, Johannigman JA. Battery life of the "four hour" lithium battery of the LTV-1000 under varying workloads. Mil Med 2008;173(8):792-795.

75. Chipman DW, Caramez MP, Miyoshi E, Kratohvil JP, and Kacmarek RM. Performance comparison of 15 transport ventilators. Respir Care 2007;52(6):740-751.

76. Blakeman TC, Branson RD. Evaluation of 4 new generation portable ventilators. Respir Care 2013;58(2):264-272.

77. Greenberg KL, Weinreb J, Shellock FG. "MR conditional" respiratory ventilator system incident in a 3-T MRI environment. Magn Reson Imaging 2011;29(8):1150-1154.

78. Peck P. Fatal MRI accident is first of its kind. http://www.webmd. com/news/20010801/fatal-mri-accident-is-first-of-its-kind. August 2001. Accessed March 21, 2013.

\section{Discussion}

Kacmarek: You said the average $\mathrm{O}_{2}$ flow on military transports is $3 \mathrm{~L} / \mathrm{min}$ ?

Blakeman: Yes, in $68 \%$ of the patients.

Kacmarek: OK. An E-size cylinder contains about $660 \mathrm{~L}$ : that's 3.5 hours of $\mathrm{O}_{2}$ per cylinder. Why go through the problem of dealing with a concentrator, which is much more expensive than E cylinders, and potentially less reliable, if you've got 3.5 hours per cylinder? Even flying from Iraq to Germany requires only a few cylinders.
Blakeman: Good point; it's about a 9-hour flight. The reason is that, in the military's eyes, if they didn't have to take $\mathrm{O}_{2}$ tanks, they wouldn't, because of the danger, which is an important issue. If they had 3 patients and they could take 3 E-size cylinders, it would be perfect, but they would prefer not to take any; this comes from the military side. In the hospital or even prehospital setting maybe they don't mind carrying a couple of $\mathrm{E}$ cylinders, but not on military transports.

Branson: The idea, Bob, is that in an immature theater or mass casualty situation, you always have electricity before you have compressed $\mathrm{O}_{2}$. The thought is that, if you have a small concentrator and a ventilator, you could provide a little bit of $\mathrm{O}_{2}$ for several patients and maintain oxygenation, which can be life-saving. The idea of the concentrator and ventilator together is for before the liquid oxygen systems or cylinders show up. What can you do if you just have electricity? And right now they're not allowed to have cylinders on the aircraft with the patient at the same time. In the bigger aircraft they have liquid oxygen systems, but some of the helicopters and smaller aircraft don't have access to $\mathrm{O}_{2}$ at all. 
INTER- AND INTRA-HOSPITAL TRANSPORT OF THE CRITICALly ILL

Blakeman: When an Israeli army medic picks up a patient in the field, right now they use no $\mathrm{O}_{2}$. They don't carry any cylinders. If their patient needs $\mathrm{O}_{2}$, too bad, they don't carry it. They do the best they can with what they have.

MacIntyre: This may be a naïve question to the respiratory therapists in the group, but I remember a case back home a couple years ago where somebody who required $\mathrm{O}_{2}$ was transported down to radiology, and while they were in the waiting area with nobody around, the $\mathrm{O}_{2}$ tank ran out and the patient was found dead. Are there gadgets you could put on the cylinders to alert you that you're low on $\mathrm{O}_{2}$ ?

Blakeman: Unfortunately, that's part of the problem. Time didn't permit me to talk much about MRI transport ventilators, but we all know they're not good. The one we have doesn't have any audible alarms.

MacIntyre: But how about just the tank?

Blakeman: There's nothing I know of that can alert us. What I want to know is where was the therapist when that incident happened?

MacIntyre: Don't go there.

Blakeman: OK. My point is that in the United States there should always be a therapist with the patient, but I understand. As far as I know there's nothing quite like that. One of the MRIsafe ventilators has a low-pressure alarm. Rich?

Branson: No, I'm not aware of anything either. It's an interesting idea. A long time ago I saw my next-door neighbor collapse in the driveway. I picked her up and put her in her house and called 911, and had started mouthto-mouth resuscitation and CPR on her and she revived. Then the paramedics showed up and started doing everything else, but I noticed that after they were there for about 10 minutes, their $\mathrm{O}_{2}$, cylinder was completely empty. I talked with Dr Bird about making some kind of device that would chirp on the regulator when gas pressure was low. Regulators are commodities; nobody wants to make something like that.

Kallet: Did you say that about $70 \%$ of the transport problems are related to poor planning?

Blakeman: Yes. That indicates that they aren't using a check sheet that asks, do you have the right drugs, do you have enough $\mathrm{O}_{2}$, are all your batteries (for the monitors and ventilator) charged, and so forth? That was what I was referring to.

Kallet: How much of that is directly related to respiratory care?

Blakeman: It was not reported. It was just noted as "equipment problems". ${ }^{1}$

Kallet: Your conclusion about the relationship between VAP and transport was that it might not be cause and effect, but just that these patients are sicker and they require transport.

Blakeman: I think it's both cause and effect. We're changing positions on these patients and laying them down flat. If we do that 6 or 8 times during their stay, there's no way, in my opinion, that $90 \%$ of them aren't going to get pneumonia.

Kallet: In Taiwan, in a nursing practice study, they did mouth suctioning before transport, just a very quick suctioning of the back of the mouth, and supposedly it decreased their VAP rate. $^{2}$

Blakeman: For transport? I could see where that probably doesn't happen enough. A lot of that comes from when we try to decontaminate the mouth with chlorhexidine, mouth suctioning, et cetera, and if it doesn't get done, whether you transport them or not, they'll get VAP. They did not address that issue in the study: just transporting versus not transporting. ${ }^{3}$

Kallet: My experience as a bedside clinician has always been that, even with monitoring cuff pressure over the course of a 12 hour shift, you usually have to put one or two $\mathrm{mL}$ of air in the cuff every 4 hours or so, apparently because of tiny leaks. In that context, transporting a supine patient, schlepping them back and forth on a stretcher, and moving them onto and off of the CT or MRI table, the chances are pretty high that they'll have some type of aspiration.

Blakeman: The protocol at our hospital is that we check cuff pressure every 12 hours. But, like you say, do they check them routinely before and after transport? No. That's a good point.

Kacmarek: If you put an endotracheal tube in a simulated trachea, inflate the cuff appropriately, put fluid above the cuff, and then tug a little on the tube, you'll be amazed at how much fluid moves right past the cuff as soon as you jerk it. Any time you move a patient and there's any kind of torque put on the airway, you immediately allow rapid aspiration of the fluid sitting above the cuff. If you very carefully suctioned prior to transport, you might reduce it, but it's pretty hard to suction all of the secretions that sit above a cuff.

Blakeman: Those subglottic suction tubes have been, in our experience, suboptimal. We just can't get them to work very well consistently.

Kallet: Another point is that, with daily sedation interruptions, particularly with neuro-trauma patients, you wake them up and often they're gasping. Several of our therapists think that 
causes VAP. You can see this tracheal tugging: they're thrashing around and the tube shifts back and forth.

Blakeman: You're right. Those patients, if you wake them up at all, they tend to be pretty wild.

Gajic: Telemedicine has been increasingly used across hospitals, but I have read nothing about the possibility of providing oversight to transport, especially these critically ill ventilated patients: a visual communication with a specialist who understands.

Blakeman: During the transport?

Gajic: During transport as well, absolutely, or when we accept a patient from the referring hospital. I am thinking that if telemedicine helps remind us what to do with the ventilator bundle, maybe it can also be used during the critical hours of transport.

Blakeman: You're talking about having visual monitoring, correct? I've discussed that with therapists, and their feeling is that big brother will be watching them every minute. They already feel like that now. Having somebody watch me doing the transport could be a bit unnerving.

Gajic: No, just as a readily available decision support when needed.

Blakeman: I understand what you're saying, but I think you'll have the same problem. That would work in the hospital, but I don't know if it would work inter-hospital or prehospital, or in the air. It's possible, and it may come to that. We don't have e-monitoring or anything like that yet at our facility.

Berra: Aspiration is a key factor, but I think that changes in oral flora are the most important feature. In fact, unperceived aspiration is not unusual even in a healthy subject, especially during the night. Indeed, oral care is of the greatest importance to prevent oral colonization from pathogens in intubated and mechanically ventilated patients.

Blakeman: Right, and that's true with any patient, whether they're being transported or not. As Rich Kallet said, there may not be a cause and effect, but there's an association there, and whether it's changing flora or not, there's still association between the two.

\section{REFERENCE}

1. Waydhas C. Intrahospital transport of critically ill patients. Crit Care 1999;3(5): R83-R89.

2. Tsai H-H, Lin F-C, Chang S-C. Intermittent suction of oral secretions before each positional change may reduce ventilatorassociated pneumonia: a pilot study. Am J Med Sci 2008;336(5):397-401.

3. Bercault N, Wolf M, Runge I, Fleury JC, Boulain T. Intrahospital transport of critically ill ventilated patients: a risk factor for ventilator-associated pneumoniamatched cohort study. Crit Care Med 2005; 33(11):2471-2478. 